\title{
Occlusal disharmony accelerates the initiation of atherosclerosis in apoE knockout rats
}

\author{
Daisuke Ekuni ${ }^{1 *}$, Toshiki Yoneda', Yasumasa Endo ${ }^{1}$, Kenta Kasuyama ${ }^{1}$, Koichiro Irie², Shinsuke Mizutani ${ }^{1}$, \\ Tetsuji Azuma', Takaaki Tomofuji ${ }^{1,3}$ and Manabu Morita ${ }^{1}$
}

\begin{abstract}
Background: Psychosocial stress is one of the risk factors for atherosclerosis. As occlusal disharmony induces psychological stress, we hypothesized that psychological stress by occlusal disharmony accelerates atherosclerosis. The aim of this study was to investigate the effects of occlusal disharmony on the initiation of atherosclerosis in apolipoprotein E (apoE) knockout rats.
\end{abstract}

Methods: Fourteen male apoE-knockout rats (age; 8 weeks) (Sprague-Dawley strain background) were divided into two groups of seven rats: the occlusal disharmony group and the no treatment (control) group. In the occlusal disharmony group, the maxillary molar cusps were cut off for the 8-week experimental period.

Results: In the occlusal disharmony group, the percentages of the area of total aortic lumen occupied by plaques and lipid were significantly higher than those in the control group ( $p<0.05, t$-test). The occlusal disharmony group also showed significantly higher serum levels of very low-density lipoprotein-cholesterol (VLDL) and low-density lipoprotein-cholesterol (LDL), plasma levels of corticosterone (1.9, 1.3 and 1.3 times, respectively), higher aortic protein expression levels of vascular cell adhesion molecule-1 (VCAM1) and intercellular adhesion molecule-1 (ICAM1) (1.5 and 1.4 times, respectively), and higher aortic gene expression of levels of VCAM1 and Toll-like receptor 4 (TLR4) (1.9 and 4.3 times, respectively), as compared to the control group $(p<0.05)$. However, there were no significant differences in serum levels of oxidized $L D L$, reactive oxygen metabolites and C-reactive protein between the two groups.

Conclusion: In apoE knockout rats, occlusal disharmony may induce VCAM1, ICAM1 and TLR4 expression and accelerate the initiation of atherosclerosis.

Keywords: Apolipoprotein E, Atherosclerosis, Occlusion, Stress, Toll-like receptor, Vascular cell Adhesion molecule-1

\section{Background}

Atherosclerosis is a chronic disease of the arterial wall that leads to death and loss of productive life years worldwide [1]. The pathogenesis of atherosclerosis can be divided into three phases: initiation, lesion progression and thrombotic complication [1]. The initial step in the development of atherosclerotic plaques is mediated, in part, by the monolayer of endothelial cells lining the inner wall of the arterial vessel [2]. According to various

\footnotetext{
* Correspondence: dekuni7@md.okayama-u.ac.jp

'Department of Preventive Dentistry, Okayama University Graduate School of Medicine, Dentistry and Pharmaceutical Sciences, 2-5-1 Shikata-cho, Kita-ku, Okayama 700-8558, Japan

Full list of author information is available at the end of the article
}

stimuli, focal areas of the endothelial monolayer are activated to express adhesion molecules, such as vascular cell adhesion molecule-1 (VCAM1) and intercellular adhesion molecule-1 (ICAM1), and capture leukocytes. After adhering to activated endothelial cells, leukocytes are recruited to enter the intima by chemoattractant signals [3]. Low-density lipoprotein-cholesterol (LDL) particles deposit in the artery wall and monocyte-derived foam cells accumulate in lesions [3]. Toll-like receptor 4 (TLR4), a critical key factor in regulating innate immune response, plays an important role in the formation of foam cells [4]. At the same time, reactive oxygen species (ROS) peroxidize lipid components, leading to the 
formation of oxidized LDL-cholesterol (ox-LDL), one of the key mediators of atherosclerosis [5].

Numerous risk factors contribute to atherosclerosis, including smoking [6], diabetes mellitus [7], dyslipidemia $[8]$, hypertension $[9,10]$ and periodontitis $[11,12]$. However, the absence of such traditional risk factors does not completely protect from the disease, which indicates additional factors involved in the development of atherosclerosis [13]. Evidence reveals that a chronic inflammatory response contributes to atherogenesis and plaque disruption, and the innate immune response plays a critical role in the initiation of this process $[14,15]$. Oxidative stress is also an important manifestation of the inflammatory responses during the atherogenesis [16].

Psychosocial stress, particularly chronic stress, is one of these nontraditional risk factors for atherosclerosis in humans $[17,18]$. Experimental studies also demonstrated that chronic stress accelerates atherosclerosis [19,20]. For example, chronic unpredictable stress accelerates atherosclerosis in apolipoprotein $\mathrm{E}$ (apoE) knockout mice [20]. However, the mechanisms leading to atherosclerosis initiation are not fully understood.

Occlusal disharmony, which includes malocclusion with reduced masticatory performance, induces psychological stress. In humans, malocclusion may contribute to psychological stress in young adults [21]. In animal models, the placement of acrylic caps on both lower incisors in rats increases plasma corticosterone levels, an indicator of psychological stress [22]. The molarless state in aged senescence-accelerated prone mice induces higher plasma corticosterone levels when compared to molar-intact control mice [23], and cutting off maxillary molar crowns increases plasma corticosterone levels in both wild-type and apoE knockout rats [24]. However, it is unclear whether psychological stress induced by occlusal disharmony is able to accelerate atherosclerosis.

We hypothesized that psychological stress induced by occlusal disharmony accelerates atherosclerosis. The aim of this study was to investigate the effects of occlusal disharmony on the initiation of atherosclerosis in apoE knockout rats as an established atherosclerosis model [20]. The main outcomes of the present study were the percentages of the area of total aortic lumen occupied by plaques and the area of lipid deposition. To clarify the mechanisms of initiation of atherosclerosis, aortic expression of VCAM1, and TLR4 and serum lipid profiles were evaluated. In addition, plasma corticosterone levels were determined as a parameter of psychological stress by occlusal disharmony [24]. Furthermore, levels of reactive oxygen metabolites (ROM) (whole oxidant capacity of serum against $\mathrm{N}, \mathrm{N}$-diethylparaphenylendiamine in acidic buffer) were determined as a marker of circulating ROS levels [25], and levels of C-reactive protein (CRP) were determined as a marker of inflammation [20].

\section{Materials and methods}

\section{Animals}

Fourteen male apoE-deficient rats (age, 8 weeks) (SpragueDawley background) were obtained from Sigma Laboratory (St. Louis, MO) for this 8-week study. Animals were housed in an air-conditioned room $\left(23-25^{\circ} \mathrm{C}\right)$ with a 12 -h light-dark cycle. Animals had free access to powdered diet (Oriental Yeast Co., Tokyo, Japan) and tap water. The experimental protocol was approved by the Animal Care and Use Committee of Okayama University (OKU-2012428).

\section{Experimental design}

Rats were randomly divided into two groups of seven rats each: a control group, which received no treatment for 8 weeks, and an occlusal disharmony group, in which all maxillary molar crowns were cut off at the gingival margin using a dental turbine for 8 weeks [26]. All procedures were performed under general anesthesia by inhalation of $2-4 \%$ isoflurane delivered in an $\mathrm{O}_{2}$ gas. Animals were sacrificed under general anesthesia after 8 weeks.

\section{Measurement of plasma corticosterone, and serum total cholesterol, triglyceride, lipoproteins, ox-LDL, ROM and CRP levels}

Plasma samples were collected from the heart at 8 weeks, between 7:00 am and 9:00 am, in tubes containing EDTA (Terumo, Tokyo, Japan) [27]. Tubes were immediately placed on ice and then centrifuged at 2,000 $\times g$ for $10 \mathrm{~min}$ at $4^{\circ} \mathrm{C}$. Supernatants were collected and stored at $-80^{\circ} \mathrm{C}$ before use. Plasma corticosterone levels were determined using an enzyme immunoassay kit (Yanaihara Institute Inc., Shizuoka, Japan) in accordance with the manufacturer's instructions.

Serum samples were separated by centrifugation at $1,500 \times g$ for $15 \mathrm{~min}$. In addition to serum total cholesterol and triglyceride, serum lipoproteins were analyzed by a gel permeation high performance liquid chromatography system at Skylight Biotech (Akita, Japan), as described previously [28]. We quantified individual subfractions using best curve fitting analysis, assuming that the particle sizes for all subfractions followed a Gaussian distribution. Particle sizes for individual subfractions were determined as $30-80 \mathrm{~nm}$ (very low-density lipoprotein-cholesterol [VLDL]), 16-30 nm (LDL) and 8-16 nm (high-dentity lipoprotein-cholesterol [HDL]) [29]. Serum ox-LDL was measured using a commercial enzyme-linked immunosorbent assay (ELISA) kit for rats (Cusabio Biotech Co., Ltd., Wuhan, China) according to the manufacturer's instructions [30]. Levels of ROM were determined using a free radical evaluator (Diacron International, Grosseto, Italy) according to previously reported analysis procedures [30]. Data are given in terms of Carratelli Units (CARR U), with 1 CARR U corresponding to $0.08 \mathrm{mg} / \mathrm{dL}$ 
hydrogen peroxide. Levels of serum CRP were also determined using a highly sensitive ELISA kit (Life Diagnostics, West Chester, PA) [31].

The measurements described above were performed in duplicate. Both intra- and inter-assay coefficients of variation were $<5 \%$.

\section{Determination of gene expression with real-time reverse transcription-polymerase chain reaction (RT-PCR)}

The descending aorta was harvested, immediately frozen and kept in RNAlater, an RNA stabilization solution (Ambion, Austin, TX) at $-80^{\circ} \mathrm{C}$ until use for real-time RT-PCR [26]. Total RNA was isolated from samples using Trizol reagent (Invitrogen, Carlsbad, CA) in accordance with the manufacturer's instructions. Isolated RNA was quantified by measurement of absorbance at $260 \mathrm{~nm}$, and purity was determined by the $260 / 280 \mathrm{~nm}$ absorbance ratio. Samples with a ratio $>1.8$ were used. Total RNA $(2 \mu \mathrm{g})$ was reverse transcribed with Avian Myeloblastosis Virus Reverse Transcriptase (Takara, Shiga, Japan) at $42^{\circ} \mathrm{C}$ for $30 \mathrm{~min}$. Prepared cDNA was diluted 10 -fold with yeast RNA $(10 \mu \mathrm{g} / \mathrm{mL})$. Real-time PCR was performed using TOYOBO SYBR Green PCR Master Mix (Toyobo, Osaka, Japan) and the Mx3000P Real-time QPCR System (Agilent Technologies, Tokyo, Japan). Amplification conditions were as follows: 45 cycles at $95^{\circ} \mathrm{C}(5 \mathrm{~s}), 65^{\circ} \mathrm{C}(5 \mathrm{~s})$ and $72^{\circ} \mathrm{C}(8 \mathrm{~s})$ for $V C A M 1$; and 45 cycles at $95^{\circ} \mathrm{C}(15 \mathrm{~s}), 59^{\circ} \mathrm{C}(20 \mathrm{~s})$ and $72^{\circ} \mathrm{C}(20 \mathrm{~s})$ for TLR4. Primer sequences were VCAM1, $5^{\prime}$-GGCTCG TACACCATCCGC-3' and $5^{\prime}$-CGGTTTTCGATTCAC ACTCGT-3' [32], and TLR4, 5' -GTGAGCATTGATG AGTTCAG-3' and 5' -CATCTAATGATTGATAAGGA TT-3' [29]. Primers used to detect the internal control, $\beta$-actin, were 5 '-TGTTGCCCTAGACTTCGAGCA-3' and 5'-GGACCCAGGAAGGAAGGCT-3' [29]. Expression of each gene is shown as the relative copy number ratio of the target gene against $\beta$-actin for each sample [29].

\section{Histological evaluation of aorta samples}

Frozen sections $(8 \mu \mathrm{m})$ were obtained from the descending aorta, embedded in Optimal Cutting Temperature compound (Tissue Tec; Miles, Naperville, IL) and stained with oil red $\mathrm{O}$, hematoxylin and eosin, as described elsewhere [32]. Immunohistochemical staining for VCAM1 or ICAM1 was performed using Histofine Simple Stain MAX PO kits (Nichirei, Tokyo, Japan) [32]. Briefly, aortic tissues were immersed in methanol containing $0.3 \%$ hydrogen peroxide for $30 \mathrm{~min}$ in order to block endogenous peroxidase activity. Sections were then treated at $4^{\circ} \mathrm{C}$ with an anti-VCAM1 (Santa Cruz Biotechnology) [32] (diluted 1:100) or ICAM1 (diluted 1:50) overnight, followed by treatment with a secondary antibody (Fab') with peroxidase complex for $30 \mathrm{~min}$. Color was developed with a solution of 3,3-diaminobenzidine in $50 \mathrm{mmol} / \mathrm{l}$ Tris- $\mathrm{HCl}$ buffer ( $\mathrm{pH}$ 7.5) containing $0.001 \%$ hydrogen peroxide and sections were counterstained with Mayer's hematoxylin. Control sections included buffer alone or nonspecific purified rabbit immunoglobulin G. Percentages of total aortic lumen area occupied by plaques per section, the total aortic lumen area occupied by lipids per section, and VCAM1- or ICAM1-positive aortic lumen area were calculated using computer-assisted image analysis software (WinROOF, Mitani Co., Fukui, Japan) [32].

\section{Statistical analysis}

All data analyses were performed using a statistical software package (PASW Statistics ver. 18.0; IBM Co., Tokyo, Japan). T-test was used for statistical comparison of the data between the control group and occlusal disharmony group. The level of significance was set at $p<0.05$.

\section{Results}

No significant differences were observed in food consumption between the two groups of rats over the experimental period. Body weights (mean \pm SD) for the control and occlusal disharmony groups were $421.4 \pm$ 29.1 and $410.0 \pm 28.9 \mathrm{~g}$, respectively, at 8 weeks. Body weights were not significantly different among the groups $(p>0.05)$.

Plasma corticosterone levels in the occlusal disharmony group were significantly higher than in the control group (1.3 times) $(p<0.05)$ (Table 1$)$. Serum VLDL and LDL levels in the occlusal disharmony group were significantly higher than those in the control group (1.9 and 1.3 times, respectively) $(p<0.05)$ (Table 1$)$. On the other hand, there were no significant differences in serum levels of oxidized LDL, ROM and CRP between the two groups $(p>0.05)$ (Table 1$)$.

Table 1 Difference in plasma/serum markers between control and occlusal disharmony groups

\begin{tabular}{lcc}
\hline Parameter & Control & $\begin{array}{c}\text { Occlusal } \\
\text { disharmony }\end{array}$ \\
\hline Corticosterone $(\mathrm{ng} / \mathrm{mL})$ & $14.2 \pm 4.9^{\mathrm{a}}$ & $28.6 \pm 12.4^{\mathrm{b}}$ \\
Total cholesterol $(\mathrm{mg} / \mathrm{dL})$ & $122.5 \pm 11.1$ & $162.8 \pm 30.8^{\mathrm{b}}$ \\
Triglyceride $(\mathrm{mg} / \mathrm{dL})$ & $48.5 \pm 12.4$ & $47.8 \pm 24.5^{\mathrm{b}}$ \\
Very low-density lipoprotein $(\mathrm{mg} / \mathrm{dL})$ & $51.4 \pm 6.1$ & $66.1 \pm 13.5^{\mathrm{b}}$ \\
Low-density lipoprotein $(\mathrm{mg} / \mathrm{dL})$ & $47.1 \pm 5.5$ & $63.0 \pm 11.6^{\mathrm{b}}$ \\
High-density lipoprotein $(\mathrm{mg} / \mathrm{dL})$ & $9.8 \pm 1.3$ & $11.0 \pm 1.7$ \\
Oxidized low density & $29.4 \pm 5.0$ & $25.8 \pm 3.1$ \\
lipoprotein (ng/mL) & & \\
Reactive oxygen metabolites & $469.3 \pm 22.2$ & $589.9 \pm 163.0$ \\
(CARR U) & & $1.0 \pm 0.2$ \\
\hline C-reactive protein (mg/L) & $1.0 \pm 0.1$ & \\
\hline
\end{tabular}

${ }^{\mathrm{a}}$ Data are expressed as means \pm SD $(n=7)$.

${ }^{\mathrm{b}} p<0.05$ (vs. control group, according to $t$-test). 
The percentage of total aortic lumen area occupied by plaques was significantly higher in the occlusal disharmony group than that in the control group $(p<0.05)$, although the plaque sizes were small and only early lesions of atherosclerosis were observed (Figure 1). The area of lipid deposition in the occlusal disharmony group was significantly higher than that in the control group (Figure 2). The VCAM1-positive area was significantly higher in the occlusal disharmony group than in the control group (1.5 times) $(p<0.05)$ (Figure 3). The ICAM1-positive area was significantly higher in the occlusal disharmony group than in the control group (1.4 times) $(p<0.05)$ (Figure 4$)$.

Gene expression of VCAM1 and TLR4 was significantly higher in the occlusal disharmony group than in the control group (1.9 and 4.3 times, respectively) $(p<0.05)$ (Table 2).

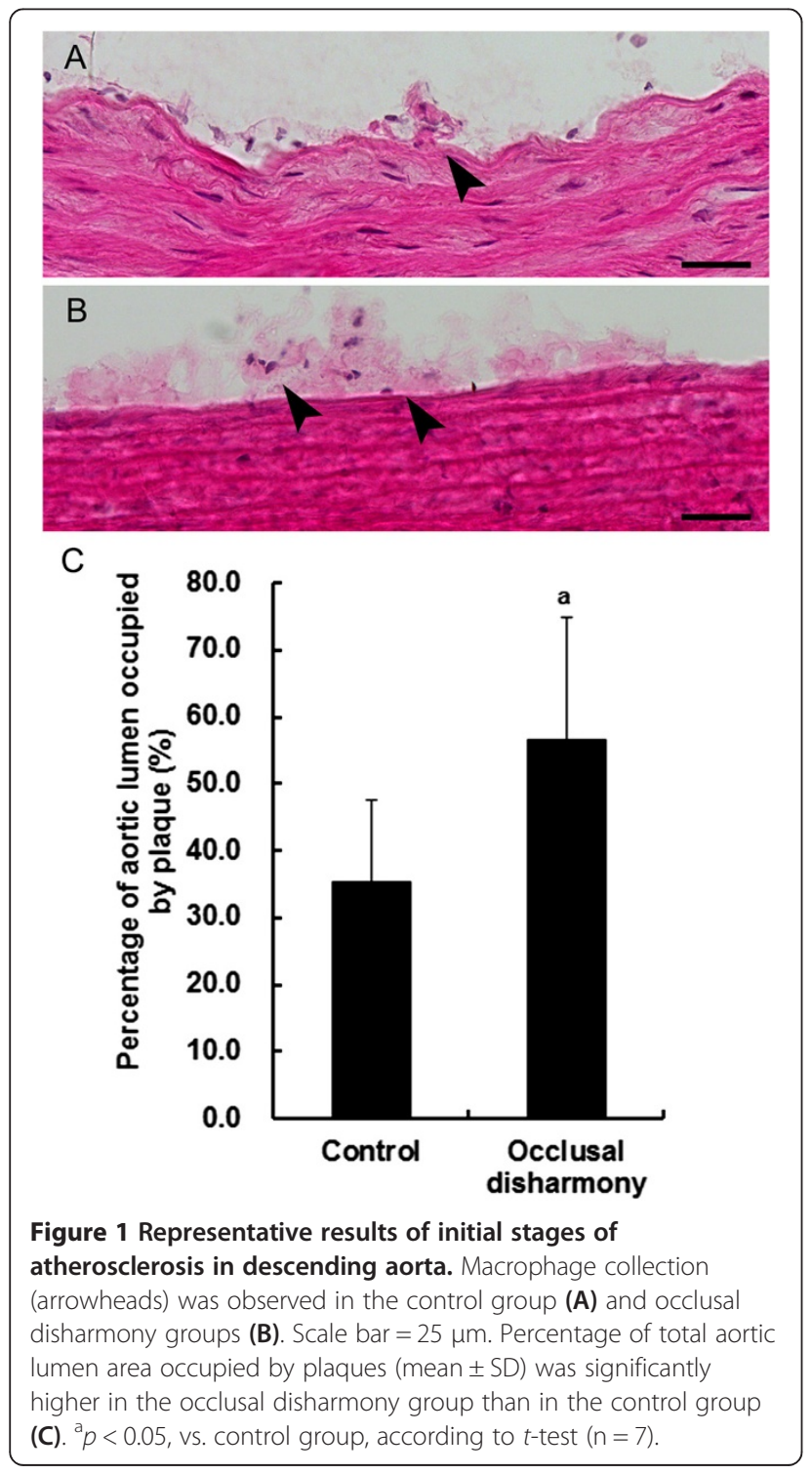

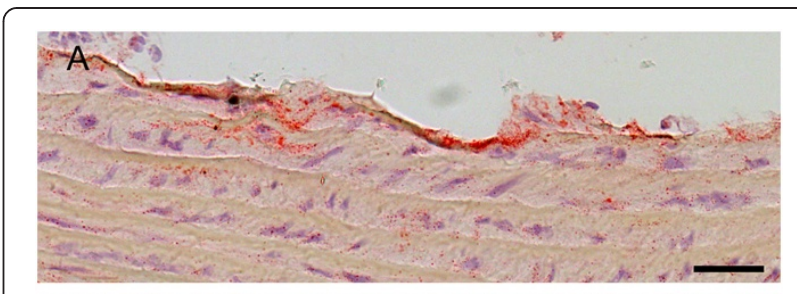

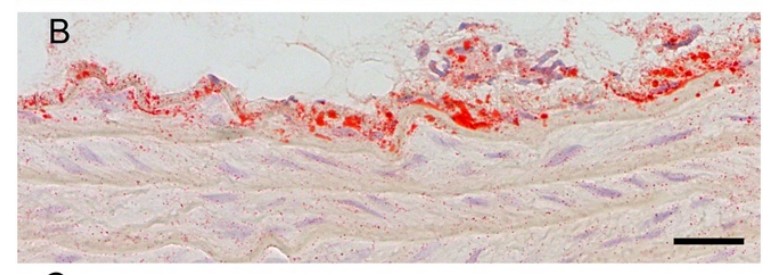

C

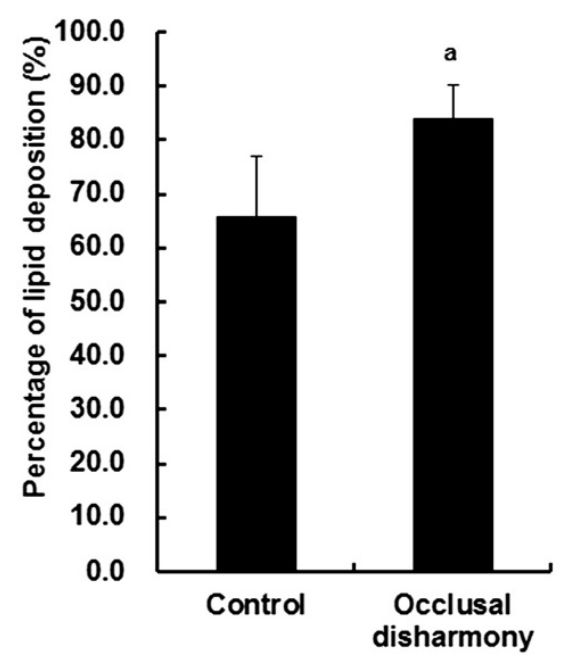

Figure $\mathbf{2}$ Lipid deposition in descending aorta. Lipid deposition (red color) in the occlusal disharmony group (B) was more intense than in the control group (A). Scale bar $=25 \mu \mathrm{m}$. Area of lipid deposition in the occlusal disharmony group (mean \pm SD) was significantly higher than in the control group (C). ${ }^{a} p<0.05$, vs. control group, according to $t$-test $(n=7)$.

\section{Discussion}

Psychosocial stress, particularly chronic stress, is a nontraditional risk factor for atherosclerosis in humans $[17,18]$. Experimental studies have also demonstrated that chronic stress accelerates atherosclerosis [19,20], and occlusal disharmony induces psychological stress [21-24]. However, the mechanisms by which occlusal disharmony accelerates the initiation of atherosclerosis are not clearly understood. To the best of our knowledge, this is the first study to assess the causal relationship between occlusal disharmony and initiation of atherosclerosis in the rat descending aorta. In this study, the occlusal disharmony group showed higher plasma levels of corticosterone than the control group. Furthermore, in the occlusal disharmony group, the percentages of total aortic lumen area occupied by plaques and lipid deposition were significantly higher 

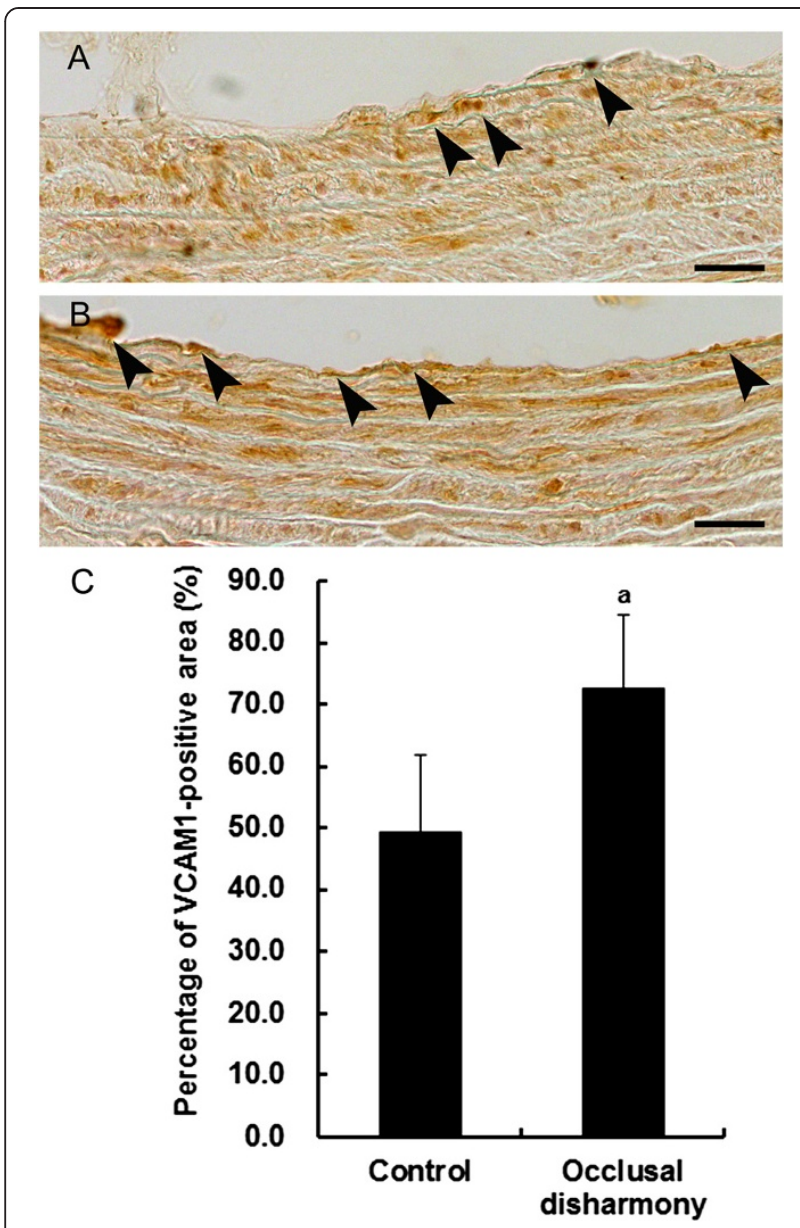

Figure 3 Vascular cell adhesion molecule-1 (VCAM1) expression in cross sections of descending aorta. VCAM1 expression in endothelial tissue (arrowheads) in the occlusal disharmony group (B) was more intense than in the control group (A). Scale bar $=25 \mu \mathrm{m}$. Percentage of VCAM1-positive lumen (mean \pm SD) in the occlusal disharmony group was significantly higher than that in the control group (C). ${ }^{a} p<0.05$, vs. control group, according to $t$-test $(n=7)$.

than those in the control group. These findings suggest that psychological stress induced by occlusal disharmony accelerated atherosclerosis.

TLR4 plays an important role in the initiation of atherosclerosis [4]. Increased expression of TLR4 within lipid-rich atherosclerotic plaques in both human and animal models has been reported [33,34]. While TLR4 was originally described as a pattern receptor that recognizes lipopolysaccharide, endogenous ligands, such as ox-LDL, fibronectin and heat shock protein, are known to be TLR4 activators [35]. Modifications of LDL, icluding ceramide-enriched LDL can induce TLR4 expression [36]. In this study, serum levels of LDL and aortic TLR4 gene expression in the occlusal disharmony were significantly higher than those in the control group. TLR4 expression following occlusal disharmony may be upregulated by LDL.

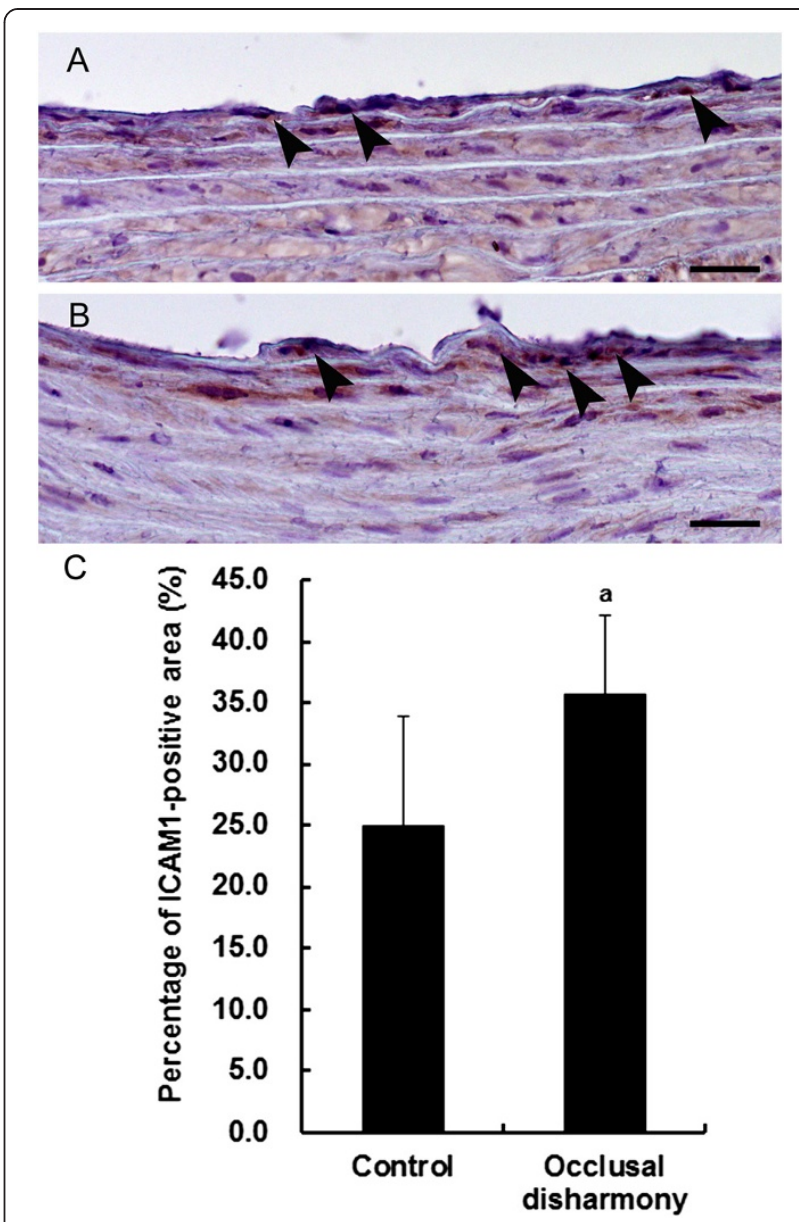

Figure 4 Intracellular adhesion molecule-1 (ICAM1) expression in cross sections of descending aorta. ICAM1 expression in endothelial tissue (arrowheads) in the occlusal disharmony group (B) was more intense than in the control group (A). Scale bar $=25 \mu \mathrm{m}$. Percentage of ICAM1-positive lumen (mean \pm SD) in the occlusal disharmony group was significantly higher than that in the control group (C). ${ }^{a} p<0.05$, vs. control group, according to $t$-test $(n=7)$.

VCAM1 and ICAM1 are endothelial adhesion molecules of the Ig gene superfamily that may participate in atherogenesis by promoting monocyte accumulation in the arterial intima [37]. Although expression of both VCAM-1 and ICAM-1 is up-regulated in atherosclerotic lesions, VCAM1, but not ICAM1, plays a dominant role in the initiation of atherosclerosis [38]. On the other

Table 2 Fold change in gene expression in rat descending aorta

\begin{tabular}{lcc}
\hline Parameter & Control & Occlusal disharmony \\
\hline Vascular cell adhesion molecule- 1 & $0.41 \pm 0.07^{\mathrm{a}}$ & $0.79 \pm 0.05^{\mathrm{b}}$ \\
Toll-like receptor 4 & $0.32 \pm 0.08$ & $1.36 \pm 0.21^{\mathrm{b}}$
\end{tabular}

${ }^{\mathrm{a}}$ Data are expressed as means \pm SD ( $\mathrm{n}=3$ independent experiments). mRNA levels were calculated in terms of relative copy number ratio for each mRNA against $\beta$-actin for each sample.

${ }^{\mathrm{b}} p<0.05$ (vs. control group, according to $t$-test). 
hand, LDL induces expression of VCAM1 in human vascular endothelial cells [39]. In this study, the protein and gene expression of VCAM1 in the aorta, the area of lipid deposition, and the serum levels for LDL were significantly higher in the occlusal disharmony group when compared to the control group. These findings suggest that LDL induced by occlusal disharmony induces VCAM1 expression and accelerates the initiation of atherosclerosis.

Although it remains unclear how corticosterone induced by occlusal disharmony contributes to up-regulation of total cholesterol or LDL in this study, there may be a possible relationship between corticosterone and regulation of lipid and lipoprotein metabolism. Exposure to low levels of corticosterone for long terms significantly exacerbates atherosclerosis in ApoE knockout mice [40]. Synthetic glucocorticoid treatment increases the expression of the enzyme 3-hydroxy-3-methyl-glutaryl-CoA reductase (HMG-CoA reductase) [41]. HMG-CoA reductase is a key regulatory enzyme in the conversion of HMG-CoA to mevalonic acid, which is a precursor for cholesterol synthesis [42]. Competitive inhibitors of HMG-CoA reductase increase the expression of LDL receptors in the liver, which decreases serum total cholesterol and LDL concentrations [43]. Taken together, these findings suggest that corticosterone exacerbates atherosclerosis by primarily up-regulating circulating levels of total cholesterol and LDL [40].

There were no significant differences in serum levels of ox-LDL and ROM between the control and occlusal disharmony groups. An increasing number of studies have demonstrated that oxidative stress plays a pivotal role in the pathogenesis of atherosclerosis [17,44]. ROS peroxidizes lipid components, leading to the formation of ox-LDL, which plays a role in the development and progression of atherosclerosis and its complications [45]. Ox-LDL is formed by oxidative stress and leads to endothelial activation and injury resulting in an inflammatory response that induces recruitment, activation and migration of monocytes through inter-endothelial gaps to the sub-endothelial region [46]. These observations have been confirmed in stress models, in which restraint stress upregulates lectin-like ox-LDL receptor-1 via formation of ROS in the aorta of apolipoprotein E-deficient mice [47]. However, our findings differed from the results of a previous study. The reasons for this discrepancy are not clear, but may depend on the type of psychological stress (restraint stress vs. occlusal disharmony) and species (mouse vs. rat).

A chronic inflammatory response contributes to atherogenesis and plays a critical role in the initiation of this process [14]. CRP is a marker of inflammation and is a strong marker for cardiovascular morbidity [48]. In this study, there were no significant differences in serum levels of CRP between the control and occlusal disharmony groups. However, in a previous study, chronic unpredictable stress accelerated atherosclerosis by increasing serum levels of CRP in apolipoprotein E knockout mice [20]. This chronic unpredictable stress included heat stimulation, cage tilting, wet bedding, lights on overnight, tail pinch, high-speed agitation, cold stimulation, overhang, water deprivation and food deprivation. These conditions significantly reduced body weight and induced 2.5 -fold higher levels of aortic VCAM1 expression [20]. The psychological stress induced by occlusal disharmony in our study is milder than the unpredictable stress in the previous study. In fact, there was no body weight loss in our stress model.

Psychosocial stress is one of the risk factors for atherosclerosis in humans $[17,18]$. Although occlusal disharmony induces psychological stress in animal [22-24] and in human [21] models, the relationship between psychological stress from occlusal disharmony and atherosclerosis is not clear in humans. Recently, cross-sectional epidemiological studies have reported on the relationship between tooth loss and atherosclerosis $[49,50]$. Number of teeth was related to atherosclerotic plaque in the carotid arteries in an elderly Swedish population [49]. A positive relationship between increased tooth loss in the posterior region and accumulation of arterial atheroma has been shown in a Korean population [50]. These results suggest that occlusal disharmony from tooth loss induces psychological stress and is a risk factor for atherosclerosis in humans. Thus, improvement of occlusal disharmony, such as through prosthodontic therapy, may contribute to the prevention and treatment of atherosclerosis. However, further studies are necessary to clarify the relationship between improved occlusal disharmony and atherosclerosis.

Our study has several limitations. In this model, only the initial stage of atherosclerosis was observed, rather than advanced lesions. Although our occlusal disharmony model that induces psychological stress was established for an 8-week experimental period [24], longer-term follow-up may provide additional information on the development of atherosclerosis. Furthermore, there is no data whether atherosclerosis is diminished by suppressing the plasma corticosterone level in our occlusal disharmony rats.

In conclusion, in the apoE knockout rats, occlusal disharmony may induce VCAM1, ICAM1 and TLR4 expression and accelerate the initiation of atherosclerosis.

\section{Abbreviations}

VCAM1: Vascular cell adhesion molecule-1; ICAM1: Intercellular adhesion molecule-1; LDL: Low-density lipoprotein; TLR4: Toll-like receptor 4;

ROS: Reactive oxygen species; ox-LDL: Oxidized LDL; apoE: Apolipoprotein E; ROM: Reactive oxygen metabolites; CRP: C-reactive protein; VLDL: Very low-density lipoprotein; HDL: High-dentity lipoprotein; ELISA: Enzyme-linked immunosorbent assay; RT-PCR: Reverse transcription-polymerase chain reaction; CARR U: Carratelli Unit; HMG-CoA reductase: 3-hydroxy-3-methyl-glutaryl-CoA reductase. 


\section{Competing interests}

The authors declare that they have no competing interests.

\section{Authors' contributions}

Conceived and designed the experiments: $D E, T$, and MM. Performed the animal experiments: YE, TA, KI, KK, and TY. Performed the PCR: TY. Perfomed other experiments: YE, KI, KK, TY, and SM. Analyzed the data: DE, and YE. Wrote the paper: DE, TT, and MM. All authors read and approved the final manuscript.

\section{Acknowledgments}

This work was supported by the Uehara Memorial Foundation, Tokyo, Japan. The authors report no conflicts of interest with regard to this study.

\section{Author details}

${ }^{1}$ Department of Preventive Dentistry, Okayama University Graduate School of Medicine, Dentistry and Pharmaceutical Sciences, 2-5-1 Shikata-cho, Kita-ku, Okayama 700-8558, Japan. ²Department of Preventive Dentistry and Dental Public Health, Aichi-Gakuin University, Kusumoto-cho, Chikusa-ku, Nagoya 464-8650, Japan. ${ }^{3}$ Advanced Research Center for Oral and Craniofacial Sciences, Okayama University Dental School, 2-5-1 Shikata-cho, Kita-ku, Okayama 700-8558, Japan.

Received: 21 May 2014 Accepted: 2 September 2014

Published: 5 September 2014

\section{References}

1. Libby P, Ridker PM, Hansson GK: Progress and challenges in translating the biology of atherosclerosis. Nature 2011, 473(7347):317-325.

2. Sun X, Belkin N, Feinberg MW: Endothelial microRNAs and atherosclerosis. Curr Atheroscler Rep 2013, 15(12):372.

3. Tabas I, Williams KJ, Boren J: Subendothelial lipoprotein retention as the initiating process in atherosclerosis: update and therapeutic implications. Circulation 2007, 116(16):1832-1844.

4. Higashimori M, Tatro JB, Moore KJ, Mendelsohn ME, Galper JB, Beasley D: Role of toll-like receptor 4 in intimal foam cell accumulation in apolipoprotein E-deficient mice. Arterioscler Thromb Vasc Biol 2011, 31(1):50-57.

5. Steinberg D, Witztum JL: Oxidized low-density lipoprotein and atherosclerosis. Arterioscler Thromb Vasc Biol 2010, 30(12):2311-2316.

6. Bernhard D, Wang XL: Smoking, oxidative stress and cardiovascular diseases-do anti-oxidative therapies fail? Curr Med Chem 2007, 14(16):1703-1712.

7. Nicolls MR, Haskins K, Flores SC: Oxidant stress, immune dysregulation, and vascular function in type I diabetes. Antioxid Redox Signal 2007, 9(7):879-889.

8. Mügge A, Brandes RP, Böger RH, Dwenger A, Bode-Böger S, Kienke S, Frölich JC, Lichtlen PR: Vascular release of superoxide radicals is enhanced in hypercholesterolemic rabbits. J Cardiovasc Pharmacol 1994, 24(6):994-998.

9. Buday A, Orsy P, Godó M, Mózes M, Kökény G, Lacza Z, Koller A, Ungvári Z, Gross ML, Benyó Z, Hamar P: Elevated systemic TGF-beta impairs aortic vasomotor function through activation of NADPH oxidase-driven superoxide production and leads to hypertension, myocardial remodeling, and increased plaque formation in apoE(-/-) mice. Am J Physiol Heart Circ Physiol 2010, 299(2):H386-H395.

10. Huang A, Sun D, Kaley G, Koller A: Superoxide released to high intra-arteriolar pressure reduces nitric oxide-mediated shear stress- and agonist-induced dilations. Circ Res 1998, 83(9):960-965.

11. Ekuni D, Tomofuji T, Sanbe T, Irie K, Azuma T, Maruyama T, Tamaki N, Murakami J, Kokeguchi S, Yamamoto T: Vitamin C intake attenuates the degree of experimental atherosclerosis induced by periodontitis in the rat by decreasing oxidative stress. Arch Oral Biol 2009, 54(5):495-502.

12. Ekuni D, Tomofuji T, Sanbe T, Irie K, Azuma T, Maruyama T, Tamaki N, Murakami J, Kokeguchi S, Yamamoto T: Periodontitis-induced lipid peroxidation in rat descending aorta is involved in the initiation of atherosclerosis. J Periodontal Res 2009, 44(4):434-442.

13. Corrado E, Rizzo M, Coppola G, Fattouch K, Novo G, Marturana I, Ferrara F, Novo S: An update on the role of markers of inflammation in atherosclerosis. J Atheroscler Thromb 2010, 17(1):1-11.

14. Libby P: Inflammation in atherosclerosis. Arterioscler Thromb Vasc Biol 2012, 32(9):2045-2051.
15. Hansson GK, Hermansson A: The immune system in atherosclerosis. Nat Immunol 2011, 12(3):204-212.

16. Meng Z, Yan C, Deng Q, Dong X, Duan ZM, Gao DF, Niu XL: Oxidized low-density lipoprotein induces inflammatory responses in cultured human mast cells via Toll-like receptor 4. Cell Physiol Biochem 2013, 31(6):842-853.

17. Rozanski A, Blumenthal JA, Davidson KW, Saab PG, Kubzansky L: The epidemiology, pathophysiology, and management of psychosocial risk factors in cardiac practice: the emerging field of behavioral cardiology. J Am Coll Cardiol 2005, 45(5):637-651.

18. Rosengren A, Hawken S, Ounpuu S, Sliwa K, Zubaid M, Almahmeed WA, Blackett KN, Sitthi-amorn C, Sato H, Yusuf S, INTERHEART investigators: Association of psychosocial risk factors with risk of acute myocardial infarction in 11119 cases and 13648 controls from 52 countries (the INTERHEART study): case-control study. Lancet 2004, 364(9438):953-962.

19. Kumari M, Grahame-Clarke C, Shanks N, Marmot M, Lightman S, Vallance P: Chronic stress accelerates atherosclerosis in the apolipoprotein E deficient mouse. Stress 2003, 6(4):297-299.

20. Zhang T, Chen Y, Liu H, Zhou Z, Zhai Y, Yang J: Chronic unpredictable stress accelerates atherosclerosis through promoting inflammation in apolipoprotein E knockout mice. Thromb Res 2010, 126(5):386-392.

21. Ekuni D, Furuta M, Irie K, Azuma T, Tomofuji T, Murakami T, Yamashiro T, Ogura T, Morita M: Relationship between impacts attributed to malocclusion and psychological stress in young Japanese adults. Eur J Orthod 2011, 33(5):558-563.

22. Yoshihara T, Matsumoto Y, Ogura T: Occlusal disharmony affects plasma corticosterone and hypothalamic noradrenaline release in rats. J Dent Res 2001, 80(12):2089-2092.

23. Onozuka M, Watanabe K, Fujita M, Tonosaki K, Saito S: Evidence for involvement of glucocorticoid response in the hippocampal changes in aged molarless SAMP8 mice. Behav Brain Res 2002, 131(1-2):125-129.

24. Ekuni D, Endo Y, Tomofuji T, Azuma T, Irie K, Kasuyama K, Morita M: Effects of apoE Deficiency and Occlusal Disharmony on Amyloid-Beta Production and Spatial Memory in Rats. PLOS ONE 2013, 8(9):e74966.

25. Ekuni D, Endo Y, Irie K, Azuma T, Tamaki N, Tomofuji T, Morita M: Imbalance of oxidative/anti-oxidative status induced by periodontitis is involved in apoptosis of rat submandibular glands. Arch Oral Biol 2010, 55(2):170-176.

26. Ekuni D, Tomofuji T, Irie K, Azuma T, Endo Y, Kasuyama K, Morita M: Occlusal disharmony increases amyloid- $\beta$ in the rat hippocampus. Neuromolecular Med 2011, 13(3):197-203.

27. Irie K, Ekuni D, Tomofuji T, Azuma T, Endo Y, Kasuyama K, Morita M: Occlusal disharmony induces BDNF level in rat submandibular gland. Arch Oral Biol 2011, 56(1):35-40.

28. Usui S, Hara Y, Hosaki S, Okazaki M: A new on-line dual enzymatic method for simultaneous quantification of cholesterol and triglycerides in lipoproteins by HPLC. J Lipid Res 2002, 43(5):805-814

29. Tomofuji T, Ekuni D, Azuma T, Irie K, Endo Y, Kasuyama K, Yoneda T, Morita M: Involvement of toll-like receptor 2 and 4 in association between dyslipidemia and osteoclast differentiation in apolipoprotein E deficient rat periodontium. Lipids Health Dis 2013, 12:1.

30. Ekuni D, Tomofuji T, Endo Y, Kasuyama K, Irie K, Azuma T, Tamaki N, Mizutani S, Kojima A, Morita M: Hydrogen-rich water prevents lipid deposition in the descending aorta in a rat periodontitis model. Arch Oral Biol 2012, 57(12):1615-1622.

31. Endo Y, Tomofuji T, Ekuni D, Irie K, Azuma T, Tamaki N, Yamamoto T, Morita M: Experimental periodontitis induces gene expression of proinflammatory cytokines in liver and white adipose tissues in obesity. J Periodontol 2010, 81(4):520-526.

32. Ekuni D, Tomofuji T, Irie K, Kasuyama K, Umakoshi M, Azuma T, Tamaki N, Sanbe T, Endo Y, Yamamoto T, Nishida T, Morita M: Effects of periodontitis on aortic insulin resistance in an obese rat model. Lab Invest 2010, 90(3):348-359.

33. Xu XH, Shah PK, Faure E, Equils O, Thomas L, Fishbein MC, Luthringer D, Xu XP, Rajavashisth TB, Yano J, Kaul S, Arditi M: Toll-like receptor-4 is expressed by macrophages in murine and human lipid-rich atherosclerotic plaques and upregulated by oxidized LDL. Circulation 2001, 104(25):3103-3108.

34. Edfeldt K, Swedenborg J, Hansson GK, Yan ZQ: Expression of toll-like receptors in human atherosclerotic lesions: a possible pathway for plaque activation. Circulation 2002, 105(10):1158-1161.

35. Catar RA, Müller G, Heidler J, Schmitz G, Bornstein SR, Morawietz H: Low-density lipoproteins induce the renin-angiotensin system and their receptors in human endothelial cells. Horm Metab Res 2007, 39(11):801-805. 
36. Estruch M, Sánchez-Quesada JL, Ordóñez-Llanos J, Benítez S: Ceramide-enriched LDL induces cytokine release through TLR4 and CD14 in monocytes. Similarities with electronegative LDL. Clin Investig Arterioscler 2014, 26(3):131-137.

37. Springer TA: Traffic signals for lymphocyte recirculation and leukocyte emigration: the multistep paradigm. Cell 1994, 76(2):301-314.

38. Cybulsky MI, liyama K, Li H, Zhu S, Chen M, liyama M, Davis V, Gutierrez-Ramos JC, Connelly PW, Milstone DS: A major role for VCAM-1, but not ICAM-1, in early atherosclerosis. J Clin Invest 2001, 107(10):1255-1262.

39. Allen S, Khan S, Al-Mohanna F, Batten P, Yacoub M: Native low density lipoprotein-induced calcium transients trigger VCAM-1 and E-selectin expression in cultured human vascular enothelial cells. J Clin Invest 1998, 101(5):1064-1075.

40. Okutsu M, Lira VA, Higashida K, Peake J, Higuchi M, Suzuki K: Corticosterone accelerates atherosclerosis in the apolipoprotein E-deficient mouse. Atherosclerosis 2014, 232(2):414-419.

41. Oda H, Suzuki Y, Shibata T, Yoshida A: Glucocorticoid-dependent induction of HMG-CoA reductase and malic enzyme gene expression by polychlorinated biphenyls in rat hepatocytes. J Nutr Biochem 1999, 10(11):644-653.

42. Siperstein MD, Fagan VM: Feedback control of mevalonate synthesis by dietary cholesterol. J Biol Chem 1966, $241(3): 602-609$.

43. Morikawa S, Umetani M, Nakagawa S, Yamazaki H, Suganami H, Inoue K, Kitahara M, Hamakubo T, Kodama T, Saito Y: Relative induction of mRNA for HMG CoA reductase and LDL receptor by five different HMG-CoA reductase inhibitors in cultured human cells. J Atheroscler Thromb 2000, 7(3):138-144.

44. Chen K, Keaney JF Jr: Evolving concepts of oxidative stress and reactive oxygen species in cardiovascular disease. Curr Atheroscler Rep 2012, 14(5):476-483.

45. Mitra S, Goyal T, Mehta JL: Oxidized LDL, LOX-1 and atherosclerosis. Cardiovasc Drugs Ther 2011, 25(5):419-429.

46. Ross R: Atherosclerosis-an inflammatory disease. N Engl J Med 1999, 340(2):115-126

47. Andersson IJ, Sankaralingam S, Davidge ST: Restraint stress up-regulates lectin-like oxidized low-density lipoprotein receptor-1 in aorta of apolipoprotein E-deficient mice. Stress 2010, 13(5):454-460.

48. Grad E, Danenberg HD: C-reactive protein and atherothrombosis: Cause or effect? Blood Rev 2013, 27(1):23-29.

49. Holmlund A, Lind L: Number of teeth is related to atherosclerotic plaque in the carotid arteries in an elderly population. $J$ Periodontol 2012, 83(3):287-291.

50. Chin UJ, Ji S, Lee SY, Ryu JJ, Lee JB, Shin C, Shin SW: Relationship between tooth loss and carotid intima-media thickness in Korean adults. J Adv Prosthodont 2010, 2(4):122-127.

doi:10.1186/1476-511X-13-144

Cite this article as: Ekuni et al.: Occlusal disharmony accelerates the initiation of atherosclerosis in apoE knockout rats. Lipids in Health and Disease 2014 13:144.

\section{Submit your next manuscript to BioMed Central and take full advantage of:}

- Convenient online submission

- Thorough peer review

- No space constraints or color figure charges

- Immediate publication on acceptance

- Inclusion in PubMed, CAS, Scopus and Google Scholar

- Research which is freely available for redistribution

Submit your manuscript at www.biomedcentral.com/submit
C Biomed Central 